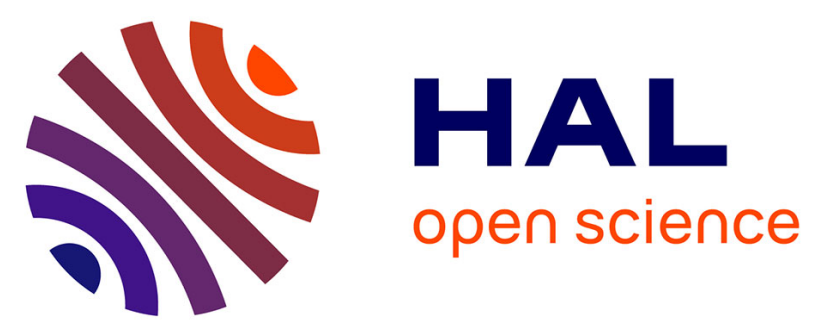

\title{
Intracellular scFvs against the viral E6 oncoprotein provoke apoptosis in human papillomavirus-positive cancer cells.
}

Magali Lagrange, Charlotte Boulade-Ladame, Laurent Mailly, Etienne Weiss, Georges Orfanoudakis, François Deryckere

\section{To cite this version:}

Magali Lagrange, Charlotte Boulade-Ladame, Laurent Mailly, Etienne Weiss, Georges Orfanoudakis, et al.. Intracellular scFvs against the viral E6 oncoprotein provoke apoptosis in human papillomaviruspositive cancer cells.. Biochemical and Biophysical Research Communications, 2007, 361 (2), pp.48792. 10.1016/j.bbrc.2007.07.040 . hal-00167371

\section{HAL Id: hal-00167371 https://hal.science/hal-00167371}

Submitted on 20 Aug 2007

HAL is a multi-disciplinary open access archive for the deposit and dissemination of scientific research documents, whether they are published or not. The documents may come from teaching and research institutions in France or abroad, or from public or private research centers.
L'archive ouverte pluridisciplinaire HAL, est destinée au dépôt et à la diffusion de documents scientifiques de niveau recherche, publiés ou non, émanant des établissements d'enseignement et de recherche français ou étrangers, des laboratoires publics ou privés. 


\section{Intracellular scFvs against the viral E6 oncoprotein provoke apoptosis in human papillomavirus-positive cancer cells}

Magali Lagrange, Charlotte Boulade-Ladame, Laurent Mailly, Etienne Weiss, Georges Orfanoudakis and François Deryckere*

UMR 7175-LC1, CNRS, Université Louis Pasteur (Strasbourg I), ESBS, Boulevard S. Brant, BP 10413, 67412 Illkirch cedex, France

* Corresponding author. Mailing address: UMR 7175-LC1, ESBS, boulevard Sébastien Brant, 67412 Illkirch, France. Phone +33 390244763 Fax: +33 390244 770. E-Mail: francois.deryckere@esbs.ustrasbg.fr

Key words: Intrabodies; scFv; HPV; E6; adenovirus; apoptosis 


\begin{abstract}
The E6 protein of Human papillomavirus type 16 (16E6) is involved in the tumorigenesis of human cervical cells by targeting numerous cellular proteins. We have designed a strategy for neutralizing 16E6 based on the intracellular expression of single-chain Fv antibodies (scFvs) specific to 16E6. Recombinant adenovirus vectors were constructed to allow expression of two 16E6-binding scFvs and one 16E6-non-binding scFv in HPV16-positive and -negative cells. Expression of the scFvs provoked two types of effects: i) inhibition of proliferation of all cell lines tested, this aspecific toxicity being likely due to the aggregation of unfolded scFvs. ii) apoptosis observed only in HPV16positive cervical cancer cell lines after expression of 16E6-binding scFvs, this specific effect being proportional to the intracellular solubility of the scFvs. These data demonstrate the feasibility of intracellular immunization with anti-16E6 scFvs and highlight the importance of the solubility of the intracellular antibodies.
\end{abstract}




\section{INTRODUCTION}

Cervical cancer is the second most common cause of cancer fatality in women worldwide. More than 99\% of these cancers are linked to viral infection with high-risk human papillomaviruses (HPVs) [1]. Epidemiological studies have demonstrated that HPV16 is the most prevalent type corresponding to more than $50 \%$ of HPVs detected in cervical cancers [2]. The oncogenic effect of these viruses is principally due to the expression of two early viral proteins, E6 and E7, which play a crucial role in immortalization and transformation of the host cells by interfering with cellular proteins involved in the regulation of the cell cycle [3]. The 16E6 is a small zinc-binding protein, the solution structure of which has revealed a novel zinc-binding fold [4]. The stimulation of the ubiquitin-mediated degradation of the p53 tumor suppressor protein via interaction with the cellular E6AP ubiquitinprotein ligase was the first described activity of the high-risk HPV E6 proteins associated with carcinogenesis [5]. However, in addition to E6AP and p53, many cellular targets of high-risk HPV E6 protein have been identified $[6,7]$ and it appears that some 16E6-induced cell-transformations in tissue culture and in vivo are independent of p53 degradation [8-10].

The 16E6 protein is sufficient to induce immortalization of human mammary epithelial cells [11] and continued expression of this protein is required for the maintenance of the transformed phenotype of HPV16-positive cervical cancer cells [12]. Therefore, 16E6 represents an ideal target for therapeutic strategies of HPV16-positive cervical carcinoma and different approaches such as antisense RNA [13-16], ribozymes [17], siRNA [18-20], peptide aptamers [21] and intracellular antibodies [22] have been used to down regulate or inactivate E6 in HPV-positive cervical cancer cells. The decrease of E6 activity observed in HPV-transformed cells led to inhibition of cellular proliferation [13, 15-17] or apoptosis $[14,18,19,21,22]$. These findings confirmed the suitability of targeting the E6 protein as a possible therapeutic approach for carcinoma of the cervix. 


\section{Materials and methods}

Cell lines. The following cell lines were used in this study: SiHa, CaSki (both derived from a HPV16 integrated human cervical carcinoma), HeLa (derived from a HPV18 integrated human cervical adenocarcinoma), A549 (derived from a human epithelial lung carcinoma). All the above cells were cultured in monolayer cultures in Dulbecco's modified Eagle's medium (DMEM) supplemented with $2 \mathrm{mM} \mathrm{L-glutamine,} 10 \%(\mathrm{v} / \mathrm{v})$ foetal calf serum, $50 \mu \mathrm{g} / \mathrm{ml}$ penicillin and $50 \mu \mathrm{g} / \mathrm{ml}$ streptomycine (Invitrogen).

Expression of scFvs and dot-blot assays. The scFvs fused to the B10 tag were expressed in the periplasm of $E$. coli XL1-Blue as described [23]. Equivalent amounts $(10 \mu \mathrm{L})$ of periplasmic extracts from bacteria transformed with scFv-expressing plasmids were loaded on SDS-PAGE and analyzed by Western blot using the B10 monoclonal antibody and peroxydase-labeled goat anti mouse IgG. Nitrocellulose strips carrying dots (50 ng) of either the Maltose Binding Protein (MBP) or 16E6 fused to MBP (MBP-E6) were incubated with $2 \mathrm{~mL}$ of periplasmic extracts. Binding of scFv to 16E6 was revealed using the B10 monoclonal antibody and peroxydase-labeled goat anti mouse $\operatorname{IgG}$.

Recombinant adenoviruses. Coding sequences of 1F4-L177P, 1F4 and 1F4-P41L scFvs fused to a B10 tag [24] under the control of the CMV promoter were inserted in replacement of the E3 region into the adenovirus 5 genome using homologous recombination in E. coli as described [25], Fig. 2A). The recombinant adenoviruses were produced and purified after transfection of 293 cells $[25]$.

Immunofluorescence analysis. Twenty-four hours after transduction with recombinant adenoviruses at a MOI of 100 plaque-forming-units (pfu)/cell, cells were fixed and analysed by immunofluorescence as previously described [26]. The scFvs were revealed by the B10 monoclonal antibody and by a FITC-conjugated anti-mouse secondary antibody. The nuclei of the cells were stained with Hoechst 33258 (Molecular Probes). 
Western blot analysis. Twenty-four hours transduction with recombinant adenoviruses at a MOI of $100 \mathrm{pfu} / \mathrm{cell}$, cells were detached with a rubber policeman and incubated $30 \mathrm{~min}$ on ice in lysis buffer $(150 \mathrm{mM} \mathrm{NaCl}, 20 \mathrm{mM}$ Tris/HCl pH8.0, $2 \mathrm{mM}$ DTT, 1\% NP-40 containing protease inhibitor mix "Complete ${ }^{\mathrm{TM}}$ " from Roche Applied Science). After a 30-min centrifugation at 12000 rpm, cellular extracts were fractionated into soluble (supernatant) and insoluble (pellet) forms. Equivalent amounts of soluble or insoluble extracts were analyzed by SDS/PAGE $12 \%$ and Western blotting. The scFvs were revealed with the B10 monoclonal antibody and peroxydase-labeled goat anti mouse IgG. The percentages of soluble and insoluble scFvs were quantified using the QuantityOne software (Bio-Rad).

Methylthiazolyldiphenyl-tetrazolium bromide (MTT) assays. To measure proliferation, cells were seeded into 96-well plates one day before transduction. At 50\% confluency, cells were transduced with recombinant adenoviruses at a MOI of 100 pfu/cell. After $12 \mathrm{~h}, 24 \mathrm{~h}$ or $48 \mathrm{~h}$ of transduction, cells were washed with PBS and incubated at $37^{\circ} \mathrm{C}$ with $100 \mu \mathrm{L}$ of a $500 \mu \mathrm{g} / \mathrm{ml} \mathrm{MTT}$ solution in media. Two hours later, the blue formazan crystals were dissolved by adding $100 \mu \mathrm{L}$ of MTT stop solution (64\% isopropanol, 32\% butanol-2, $40 \mathrm{mM} \mathrm{HCl}$ ) and the absorbance at 595nm was measured.

Apoptosis. Cells were stained with annexin V-FITC (Annexin V-FLUOS Staining kit, Roche Diagnostics) and propidium iodide according to the manufacturer instructions $24 \mathrm{~h}$ or $48 \mathrm{~h}$ after transduction by recombinant adenoviruses at a MOI of $100 \mathrm{pfu} / \mathrm{cell}$. Cells were analysed on a FACScalibur (BD-Biosciences) using a dual filter for FITC and propidium iodide. In this test, live, apoptotic and necrotic cells are distinguished on the basis of annexin V-FITC binding and PI exclusion: live cells are not stained with any of the reagents, apoptotic cells are positive for annexin $\mathrm{V}$ binding and negative for PI whereas necrotic cells are stained with both reagents 


\section{RESULTS AND DISCUSSION}

scFvs are small functional antibody fragments consisting of the heavy and light chain variable $\left(\mathrm{V}_{\mathrm{H}}\right.$ and $\mathrm{V}_{\mathrm{L}}$ ) segments held together by a flexible linker that possess the binding and specificity of the whole antibody [27]. During the antibody production, the formation of intra- and inter-chain disulfide bonds inside the endoplasmic reticulum allows the stabilization of each immunoglobulin domain and the assembly of heavy and light chains. The intracellular immunization strategy [28] aimed at neutralizing an antigen inside cells with intracellular scFvs (intrabodies) [29] requires the expression of functional scFvs in the cytoplasm of the target cells. However, the reducing environment of this compartment does not allow the formation of intra-domain disulfide bonds within the $\mathrm{V}_{\mathrm{H}}$ and $\mathrm{V}_{\mathrm{L}}$ [3032]. As a result the main challenge of intracellular immunization remains the correct folding and stability of scFvs expressed in the cytoplasm. In previous reports, we described monoclonal and single-chain antibodies against 16E6 [23, 26, 33, 34] and we evaluated here the potential of 16E6specific intrabodies for intracellular immunization of HPV-positive cancer cells using recombinant adenoviruses. We previously reported the construction of $1 \mathrm{~F} 4 \mathrm{scFv}$ which binds to the N-terminus of 16E6 [23]. To test its capacity to function as an intrabody, we investigated its solubility and activity when expressed in the cytoplasm of E. coli [34] or COS cells [35]. We found that a strong expression of 1F4 in the cytoplasm of E. coli or COS cells resulted in nearly $100 \%$ of non-folded, aggregated and insoluble scFv [35]. This aggregation was toxic for the transfected COS cells and resulted in aspecific cell death. To overcome this problem, a random mutagenesis of $1 \mathrm{~F} 4$ was performed in an attempt to isolate scFvs that would be more stable when expressed in the cytoplasm. This allowed us to isolate two scFvs each presenting one point mutation, i.e. 1F4-L177P [34] and 1F4-P41L (EW, unpublished results). The 1F4-L177P (L47P in $\mathrm{V}_{\mathrm{L}}$ ) had lost the capacity to bind to E6 and still aggregated when expressed in the cytoplasm whereas 1F4-P41L (P41L in $\mathrm{V}_{\mathrm{H}}$ ) still bound to E6 (Fig. 1B) and had an increased solubility after cytoplasmic expression (EW, unpublished results). The three scFvs were expressed in E. coli and we confirmed, using a dot-blot assay, that $1 \mathrm{~F} 4$ and 1F4- 
P41L did bind to 16E6 whereas 1F4-L177P did not (Fig. 1B).

As plasmid transfection efficiency can be very variable from one human cell line to another, we chose to use a vector derived from adenovirus type 5, known for its very high gene transfer efficacy. Coding sequences of 1F4-L177P, 1F4 and 1F4-P41L were inserted into the adenovirus type 5 genome to obtain three recombinant viruses, namely Ad1F4-L177P, Ad1F4 and Ad1F4-P41L. To assess the intracellular immunization potential of the 16E6-specific scFvs we employed two HPV16transformed cell lines, SiHa and CaSki, and two control cell lines, A549 and HeLa. HeLa cells are transformed by HPV18 and express 18E7 and 18E6, 18E6 is not recognized by the scFvs reported here [23]. The four different cell lines were transduced with the scFv-expressing vectors (Ad1F4L177P, Ad1F4 and Ad1F4-P41L) and analyzed 24 hours later by immunofluorescence. The use of a MOI of $100 \mathrm{pfu} / \mathrm{cell}$ allowed expression of the scFv in nearly $100 \%$ of the cells (Fig. 2B). In these conditions, we observed a lower level of scFv-production per cell than in COS cells transfected with scFv-expressing plasmid [35]. A higher MOI gave a stronger expression of the scFvs resulting in a high aspecific toxicity and a lower MOI resulted in a weaker percentage of cells transduced (data not shown).

After validating the high gene transfer efficacy of the scFv-encoding adenoviruses, we determined the solubility of each 16E6-intrabody by Western blotting of cellular extracts (Fig. 2C). Although the majority of the scFvs were present into the insoluble fraction of cellular extracts, the relative proportion of soluble intrabodies was higher in this study $(5-10 \%$; Fig. 2C) than in previous results with transfected COS cells $(<1 \%)$ [35]. This global higher solubility of scFvs was due to a lower expression in the human cell lines after transduction with recombinant adenoviruses at a MOI of $100 \mathrm{pfu} /$ cell than in COS cells after plasmid transfection (data not shown). The intracellular solubility of 1F4-P41L (9.9\%) was nearly twice as high as the solubility of 1F4-L177P (5.2\%) and $1 \mathrm{~F} 4(5.6 \%)$ 
We next investigated the effects of the expression of the anti-16E6 intrabodies on the proliferation of HPV16-positive cancer cell lines using a methylthiazolyldiphenyl-tetrazolium bromide (MTT) assay (Fig. 3A). In all cases, there was a strong inhibition of proliferation of the cell lines tested after expression of the scFvs, even with the negative control scFv (1F4-L177P) and negative control cell lines (HeLa and A549, Fig. 3A). This was very likely due to the toxic effect of the aggregation of unfolded intrabodies even though not as strong as was observed earlier with transfected COS cells [35]. However in addition to this non-specific effect we observed a specific effect namely that the intracellular expression of E6-binding scFvs (1F4 and 1F4-P41L) provoked cell death in HPV-positive cells (SiHa and CaSki) whereas the 1F4-L177P did not. Interestingly, the increased cytosolic solubility of the 1F4-P41L intrabody correlated with a more pronounced specific cell death in HPV16-positive cervical cells.

To further analyze the observed cell death, cells were stained with annexin V-FITC/propidium iodide (PI) and examined by flow cytometry (Fig. 3A). HeLa, A549, SiHa and CaSki cells were analyzed $24 \mathrm{~h}$ or $48 \mathrm{~h}$ after transduction by the scFv-expressing adenoviruses. Intracellular expression of the three scFvs in HPV16-negative cell lines led to a very small increase of apoptotic cells when compared to non-transduced cells $(1-3 \%$ at $48 \mathrm{~h}$, Fig. 3B). Similarly the negative control intrabody, 1F4-L177P, did not enhance apoptotic cell rates significantly. In contrast, transduction of 1F4 and 1F4-P41L increased apoptosis specifically in HPV16-transformed cells (up to 13.9\% with 1F4-P41L in CaSki), this effect being proportional to the intracellular solubility of the intrabody. Of note, the proportion of apoptotic cells induced by the 1F4-P41L was 9.5 fold higher in the HPV16-positive CaSki cells than in HeLa cells. Our results corroborate previous reports showing that targeting E6 with either antisense RNA [14], peptide aptamer [21], siRNA [18] or transfection of intrabodies [22] provokes apoptosis in HPV16-transformed cells. However the apoptosis induced by the 1F4-P41L intrabody in SiHa or CaSki cells was not strictly correlated with an increase in p53 protein level as assayed by immunofluorescence or Western blot (data not shown), the precise pathway involved in 
the apoptosis that we observed remains to be investigated.

This work demonstrates the feasibility of intracellular immunization with anti-16E6 scFvs for specific killing of cervical cancer cells. Our study was greatly facilitated by the use of adenovirus as a gene transfer and expression vector. This vector not only allowed the expression of the $\mathrm{scFv}$ uniformly in all the cells transduced in vitro (Fig. 2B) but also provides a useful vector for expression of scFv in vivo for instance for preclinical studies in animal models. The importance of intracellular solubility of intrabodies is shown by the fact that increased cytosolic solubility of the 1F4-P41L intrabody was correlated with increased specific cell death in HPV16-positive cervical cells. It may therefore be worthwhile to further improve the intracellular solubility of anti-E6 scFvs by using protein-engineering approaches [36-39] since this could lead to the development of scFvs with improved therapeutic potential against cervical carcinoma. 


\section{Acknowledgements}

We thank Claude Kedinger for his encouragement and support. We acknowledge Claudine Ebel for assistance with the FACS experiments. We thank Marc van Regenmortel, Philip Robinson, Murielle Masson and Gilles Travé for comments and critical reading of the manuscript. This work was supported by the Université Louis Pasteur de Strasbourg, the Centre National de la Recherche Scientifique, the Association pour la Recherche contre le Cancer, the Ligue Nationale Contre Le Cancer Comité du Haut Rhin and the Cancéropôle-Grand-EST. M.L. and C.B-L. were supported by scholarships of the Ministère de la Recherche (M.L. and C.B-L.) and the Ligue Régionale Contre le Cancer (ML). 


\section{References}

[1] J.M. Walboomers, M.V. Jacobs, M.M. Manos, F.X. Bosch, J.A. Kummer, K.V. Shah, P.J. Snijders, J. Peto, C.J. Meijer, N. Munoz, Human papillomavirus is a necessary cause of invasive cervical cancer worldwide, J Pathol 189 (1999) 12-19.

[2] N. Munoz, F.X. Bosch, X. Castellsague, M. Diaz, S. de Sanjose, D. Hammouda, K.V. Shah, C.J. Meijer, Against which human papillomavirus types shall we vaccinate and screen? The international perspective, Int J Cancer 111 (2004) 278-285.

[3] H. zur Hausen, Papillomavirus infections--a major cause of human cancers, Biochim Biophys Acta 1288 (1996) F5578.

[4] Y. Nomine, M. Masson, S. Charbonnier, K. Zanier, T. Ristriani, F. Deryckere, A.P. Sibler, D. Desplancq, R.A. Atkinson, E. Weiss, G. Orfanoudakis, B. Kieffer, G. Trave, Structural and functional analysis of E6 oncoprotein: insights in the molecular pathways of human papillomavirus-mediated pathogenesis, Mol Cell 21 (2006) 665-678.

[5] M. Scheffner, B.A. Werness, J.M. Huibregtse, A.J. Levine, P.M. Howley, The E6 oncoprotein encoded by human papillomavirus types 16 and 18 promotes the degradation of p53, Cell 63 (1990) 1129-1136.

[6] M.S. Longworth, L.A. Laimins, Pathogenesis of human papillomaviruses in differentiating epithelia, Microbiol Mol Biol Rev 68 (2004) 362-372.

[7] F. Mantovani, L. Banks, The human papillomavirus E6 protein and its contribution to malignant progression, Oncogene 20 (2001) 7874-7887.

[8] T. Kiyono, S.A. Foster, J.I. Koop, J.K. McDougall, D.A. Galloway, A.J. Klingelhutz, Both Rb/p16INK4a inactivation and telomerase activity are required to immortalize human epithelial cells, Nature 396 (1998) 84-88.

[9] J.P. Liu, Studies of the molecular mechanisms in the regulation of telomerase activity, Faseb J 13 (1999) 2091-2104.

[10] S. Song, H.C. Pitot, P.F. Lambert, The human papillomavirus type 16 E6 gene alone is sufficient to induce carcinomas in transgenic animals, J Virol 73 (1999) 5887-5893.

[11] V. Band, J.A. De Caprio, L. Delmolino, V. Kulesa, R. Sager, Loss of p53 protein in human papillomavirus type 16 E6-immortalized human mammary epithelial cells, J Virol 65 (1991) 6671-6676.

[12] S.I. Wells, D.A. Francis, A.Y. Karpova, J.J. Dowhanick, J.D. Benson, P.M. Howley, Papillomavirus E2 induces senescence in HPV-positive cells via pRB- and p21(CIP)-dependent pathways, Embo J 19 (2000) 5762-5771.

[13] L.M. Alvarez-Salas, T.E. Arpawong, J.A. DiPaolo, Growth inhibition of cervical tumor cells by antisense oligodeoxynucleotides directed to the human papillomavirus type 16 E6 gene, Antisense Nucleic Acid Drug Dev 9 (1999) 441-450.

[14] C.W. Cho, H. Poo, Y.S. Cho, M.C. Cho, K.A. Lee, S.J. Lee, S.N. Park, I.K. Kim, Y.K. Jung, Y.K. Choe, Y.I. Yeom, I.S. Choe, Y. Yoon do, HPV E6 antisense induces apoptosis in CaSki cells via suppression of E6 splicing, Exp Mol Med 34 (2002) 159-166.

[15] K. Hamada, M. Sakaue, R. Alemany, W.W. Zhang, Y. Horio, J.A. Roth, M.F. Mitchell, Adenovirus-mediated transfer of HPV 16 E6/E7 antisense RNA to human cervical cancer cells, Gynecol Oncol 63 (1996) 219-227.

[16] F. Venturini, J. Braspenning, M. Homann, L. Gissmann, G. Sczakiel, Kinetic selection of HPV 16 E6/E7-directed antisense nucleic acids: anti-proliferative effects on HPV 16-transformed cells, Nucleic Acids Res 27 (1999) 1585-1592.

[17] L.M. Alvarez-Salas, A.E. Cullinan, A. Siwkowski, A. Hampel, J.A. DiPaolo, Inhibition of HPV-16 E6/E7 immortalization of normal keratinocytes by hairpin ribozymes, Proc Natl Acad Sci U S A 95 (1998) 1189-1194.

[18] K. Butz, T. Ristriani, A. Hengstermann, C. Denk, M. Scheffner, F. Hoppe-Seyler, siRNA targeting of the viral E6 oncogene efficiently kills human papillomavirus-positive cancer cells, Oncogene 22 (2003) 5938-5945.

[19] K. Yamato, J. Fen, H. Kobuchi, Y. Nasu, T. Yamada, T. Nishihara, Y. Ikeda, M. Kizaki, M. Yoshinouchi, Induction of cell death in human papillomavirus 18-positive cervical cancer cells by E6 siRNA, Cancer Gene Ther 2 (2005) 2.

[20] M. Yoshinouchi, T. Yamada, M. Kizaki, J. Fen, T. Koseki, Y. Ikeda, T. Nishihara, K. Yamato, In vitro and in vivo growth suppression of human papillomavirus 16-positive cervical cancer cells by E6 siRNA, Mol Ther 8 (2003) 762-768.

[21] K. Butz, C. Denk, A. Ullmann, M. Scheffner, F. Hoppe-Seyler, Induction of apoptosis in human papillomaviruspositive cancer cells by peptide aptamers targeting the viral E6 oncoprotein, Proc Natl Acad Sci U S A 97 (2000) 6693-6697.

[22] H. Griffin, R. Elston, D. Jackson, K. Ansell, M. Coleman, G. Winter, J. Doorbar, Inhibition of papillomavirus protein function in cervical cancer cells by intrabody targeting, J Mol Biol 355 (2006) 360-378.

[23] C. Giovane, G. Travé, A. Briones, Y. Lutz, B. Wasylyk, E. Weiss, Targetting of the N-terminal domain of the human papillomavirus type 16 E6 oncoprotein with monomeric ScFvs blocks the E6-mediated degradation of cellular p53, J Mol Recognit 12 (1999) 141-152.

[24] G. Orfanoudakis, B. Karim, D. Bourel, E. Weiss, Bacterially expressed Fabs of monoclonal antibodies neutralizing tumour necrosis factor alpha in vitro retain full binding and biological activity, Mol Immunol 30 (1993) 1519-1528.

[25] C. Chartier, E. Degryse, M. Gantzer, A. Dieterle, A. Pavirani, M. Mehtali, Efficient generation of recombinant adenovirus vectors by homologous recombination in Escherichia coli, J Virol 70 (1996) 4805-4810. 
[26] M. Lagrange, S. Charbonnier, G. Orfanoudakis, P. Robinson, K. Zanier, M. Masson, Y. Lutz, G. Trave, E. Weiss, F. Deryckere, Binding of human papillomavirus 16 E6 to p53 and E6AP is impaired by monoclonal antibodies directed against the second zinc-binding domain of E6, J Gen Virol 86 (2005) 1001-1007.

[27] J.S. Huston, D. Levinson, M. Mudgett-Hunter, M.S. Tai, J. Novotny, M.N. Margolies, R.J. Ridge, R.E. Bruccoleri, E. Haber, R. Crea, et al., Protein engineering of antibody binding sites: recovery of specific activity in an anti-digoxin single-chain Fv analogue produced in Escherichia coli, Proc Natl Acad Sci U S A 85 (1988) 5879-5883.

[28] S. Biocca, P. Pierandrei-Amaldi, N. Campioni, A. Cattaneo, Intracellular immunization with cytosolic recombinant antibodies, Biotechnology (N Y) 12 (1994) 396-399.

[29] M.N. Lobato, T.H. Rabbitts, Intracellular antibodies as specific reagents for functional ablation: future therapeutic molecules, Curr Mol Med 4 (2004) 519-528.

[30] S. Biocca, A. Cattaneo, Intracellular immunization: antibody targeting to subcellular compartments, Trends Cell Biol 5 (1995) 248-252.

[31] A.P. Sibler, J. Courtete, C.D. Muller, G. Zeder-Lutz, E. Weiss, Extended half-life upon binding of destabilized intrabodies allows specific detection of antigen in mammalian cells, Febs J 272 (2005) 2878-2891.

[32] A. Worn, A. Pluckthun, Different equilibrium stability behavior of ScFv fragments: identification, classification, and improvement by protein engineering, Biochemistry 38 (1999) 8739-8750.

[33] M. Masson, C. Hindelang, A.P. Sibler, G. Schwalbach, G. Trave, E. Weiss, Preferential nuclear localization of the human papillomavirus type 16 E6 oncoprotein in cervical carcinoma cells, J Gen Virol 84 (2003) 2099-2104.

[34] G. Schwalbach, A.P. Sibler, L. Choulier, F. Deryckere, E. Weiss, Production of fluorescent single-chain antibody fragments in Escherichia coli, Protein Expr Purif 18 (2000) 121-132.

[35] A.P. Sibler, A. Nordhammer, M. Masson, P. Martineau, G. Trave, E. Weiss, Nucleocytoplasmic shuttling of antigen in mammalian cells conferred by a soluble versus insoluble single-chain antibody fragment equipped with import/export signals, Exp Cell Res 286 (2003) 276-287.

[36] P. Martineau, J.M. Betton, In vitro folding and thermodynamic stability of an antibody fragment selected in vivo for high expression levels in Escherichia coli cytoplasm, J Mol Biol 292 (1999) 921-929.

[37] K. Proba, A. Worn, A. Honegger, A. Pluckthun, Antibody scFv fragments without disulfide bonds made by molecular evolution, J Mol Biol 275 (1998) 245-253.

[38] T. Tanaka, M.N. Lobato, T.H. Rabbitts, Single domain intracellular antibodies: a minimal fragment for direct in vivo selection of antigen-specific intrabodies, J Mol Biol 331 (2003) 1109-1120.

[39] E. Tse, M.N. Lobato, A. Forster, T. Tanaka, G.T. Chung, T.H. Rabbitts, Intracellular antibody capture technology: application to selection of intracellular antibodies recognising the BCR-ABL oncogenic protein, J Mol Biol 317 (2002) $85-94$. 
Fig. 1. Expression of scFvs in E. coli and detection of 16E6. (A) Equivalent amounts (10 $\mu \mathrm{L})$ of periplasmic extracts from bacteria transformed with plasmids expressing either 1F4-L177P, 1F4 or 1F4-P41L were loaded on SDS-PAGE and analyzed by Western blot using the B10 antibody and HRP-anti mouse antibody. (B) E. coli expressed scFvs were tested for binding to 16E6. Periplasmic extracts $(2 \mathrm{~mL})$ were incubated on dot-blots carrying the Maltose Binding Protein (MBP) or 16E6 fused to MBP (MBP-E6). The minus (-) symbol refers to control performed with periplasmic extracts from XL1-Blue transformed with the empty expression plasmid. Bound scFvs were detected with the B10 antibody and HRP-anti mouse antibody.

Fig. 2. Expression of scFvs 1F4-L177P, 1F4 and 1F4-P41L. (A) Schematic representation of the recombinant adenoviral genomes. (B) Immunofluorescence detection of the expressed scFvs. Twenty-four hours after transduction with Ad1F4-L177P, Ad1F4 or Ad1F4-P41L at a MOI of 100, cells were fixed and analysed by immunofluorescence as described in the materials and methods. Non-transduced cells (nt) served as a negative control. (C) Solubility of expressed scFvs in HeLa, A549, SiHa and CaSki cells. Equivalent amounts of soluble or insoluble extracts were analyzed by Western blotting. The percentages of soluble and insoluble scFvs were quantified by VersaDoc (BioRad). The average of solubility of each $\mathrm{scFv}$ from 3 independent experiments for the four cell lines. Error bars are standard deviations.

Fig. 3: Effects of the anti-16E6 scFv in HPV16-transformed cell lines. (A) The proliferation of HeLa, A549, SiHa and CaSki cells were measured using the MTT assay $12 \mathrm{~h}, 24 \mathrm{~h}$ or $48 \mathrm{~h}$ of transduction with either Ad1F4-L177P, Ad1F4, Ad1F4-P41L or medium only (non-transduced : nt). The absorbance of formazan products at $595 \mathrm{~nm}$ reflect the number and viability of the cells. (B) Example of apoptosis analysis, $48 \mathrm{~h}$ after transduction. Apoptotic and necrotic cells were distinguished on the basis of annexin V-FITC reactivity and PI exclusion. Live, non-apoptotic cells are not stained with any of the reagents (lower left hand quadrant). Apoptotic cells exhibited intense green (FITC) and low or intermediate red (PI) fluorescence (lower right hand quadrant, early and late stages of 
apoptosis, respectively). Necrotic cells are positive with both reagents and exhibit strong green and red fluorescence (upper right hand quadrant). (C) The mean values, calculated from five independent experiments, of apoptotic cells (annexin-V-FITC positive, IP-negative) are represented. The negative control values (percentages of apoptotic cells in non-transduced cells) were subtracted from the indicated percentages. Error bars are standard deviations. 